(p. 489). Pure spéculation intellectuelle évidemment, en réaction aux privilèges exorbitants donnés au créateur individuel de l'époque romantique. Car il existe bel et bien une histoire de la notion d'auteur dont on peut plus ou moins dater l'origine, tracer l'évolution, montrer le triomphe et constater la décadence chez les structuralistes et les déconstructeurs. Les reproches qu'adressait Proust à Sainte-Beuve doivent se mesurer avec prudence aujourd'hui (voir notre « Pour Sainte-Beuve : 1804-1904-2004. Propos d'un seiziémiste $\gg$ dans la Revue d'histoire littéraire de la France, 2004, 1, p. 3-24). Il faut bien l'avouer, « tout écrivain cherche à former de luimême, à partir de l'œuvre qu' il écrit, un portrait avantageux » (491), même lorsqu'il pratique l'autodérision. Ce qui est vrai du $\mathrm{XIX}^{\mathrm{e}}$ siècle l'était déjà mutatis mutandis dans une large mesure à la Renaissance. Montaigne offre sans doute le meilleur exemple de cette soif de se faire apprécier, de laisser à son lecteur une image flatteuse de lui-même sans qu'on puisse vraiment le lui reprocher. Et l'on comprend que ce beau volume se termine par des réflexions sur la manière dont l'auteur des Essais nous parle de ses retours en arrière qui sont aussi des marches en avant (496).

FRANÇOIS RIGOLOT, Princeton University

\title{
LA CHAPELLE
}

\section{Mémoires pour servir à l'histoire de la vie d'Agrippa d'Aubigné}

Texte présenté, établi et annoté par Gilles Banderier. Paris : Honoré Champion, 2008, $117 \mathrm{p}$.

Avec les Mémoires pour servir à l'histoire de la vie d'Agrippa d'Aubigné, La Chapelle nous procure ce qu'il faut bien appeler la première biographie de l'écrivain huguenot. Fondateur à bien des égards d'une image qui marquera de son empreinte au moins deux siècles de la réception albinéenne, découvert et savamment édité par Gilles Banderier, ce texte existe sous deux formes manuscrites, dont l'une déposée à la Bibliothèque nationale de France et l'autre, version de référence de la présente édition, archivée à l'École militaire de Paris. Probablement composés à une date postérieure à 1685 , ces Mémoires sont le fruit de recherches menées par un certain La Chapelle, qui sur ordre des descendants d'A. d'Aubigné, les Villette-Mursay et Mme de Maintenon, instruisit le dossier biographique. Si La Chapelle reste totalement inconnu, son travail sous forme de « biographie autorisée » (14) ne manque pas d'intérêt, intérêt que G. Banderier relève dans une introduction aussi 
nourrie que probante. Le texte passa ultérieurement aux mains du savant Antoine de Lancelot.

Les Mémoires reproduits avec les variantes du manuscrit de la Bibliothèque nationale de France, suivis d'un index des noms et des lieux, retracent donc sur un mode apologétique la vie du soldat huguenot, tout en gardant le silence le plus complet sur l'écrivain, dont l'importance dans les Lettres ne sera saluée qu'au XIX siècle avec Sainte-Beuve. La Chapelle avait-il seulement feuilleté Les Tragiques, lui qui ne semble connaître le poète que d'après un recueil collectif de poésies du début du XVII ${ }^{\mathrm{e}}$ siècle ? Conformément à la volonté de la famille, tout dans cette vie reste déterminé par la célébration continue du fidèle serviteur d'Henri Iv. À cet effet, La Chapelle puise à pleines mains dans la première édition de l'Histoire Universelle et le manuscrit de $\mathrm{Sa}$ Vie à ses enfants. Le résultat en est éloquent, bien que profondément incomplet. Toute la partie de la vie d'A. d'Aubigné, ultérieure à la conversion d'Henri IV et à l'Édit de Nantes, est expédiée en quelques pages, afin de ne pas ternir l'image officiellement requise : aux yeux du lecteur, d'Aubigné doit rester un gentilhomme exemplaire entièrement dévoué au premier Bourbon, d'autant plus que pour Mme de Maintenon la légitimité de l'extraction aristocratique de l'ancêtre ne saurait souffrir aucune entorse généalogique au moment de son alliance avec Louis XIV. C'est dire aussi, et G. Banderier le souligne nettement, à quel point ce texte souffre de diverses maladresses de composition (développements exagérés d'anecdotes mineures), de défauts de style (nombreuses négligences), d'inexactitudes, voire d'invraisemblances (le nom de la femme et des filles, la date de la mort d'A. d'Aubigné, etc.) L'annotation du texte éclaire tous ces aspects, qui forgent le mythe personnel de l'écrivain un demi-siècle après sa mort à Genève. L'image en est aseptisée, réduite à la seule noblesse et au service exclusif de la monarchie. Pas un traître mot sur le « brouillon $\gg$, ou le « calviniste » désigné joliment comme un de ces esprits « frapés d'une maladie épidemique qui faisoit soupirer la France » en ces temps-là (95). La présente édition permet au lecteur de se familiariser en parfaite connaissance de cause avec le premier essai biographique et les débuts de l'histoire de la réception d'A. d'Aubigné.

GILBERT SCHRENCK, Université Marc Bloch-Strasbourg II 